\title{
СТАТИСТИЧЕСКАЯ ОЦЕНКА ПОСЛЕДСТВИЙ КОВИД-КРИЗИСА ДЛЯ ПЕРВИЧНОГО РЫНКА ЛЕГКОВЫХ АВТОМОБИЛЕЙ РОССИИ
}

\section{(C) 2021 Петров Александр Михайлович}

Департамент бизнес-аналитики, профессор, доктор экономических наук, доцент Финансовый университет при правительстве Российской Федерации, Россия, Москва E-mail: ampetrov@fa.ru

\section{(C) 2021 Цыпин Александр Павлович}

Департамент бизнес-аналитики, доцент, кандидат экономических наук, доцент Финансовый университет при правительстве Российской Федерации, Россия, Москва E-mail: aptsypin@fa.ru

\section{(c) 2021 Гаджимирзоев Гаджимирзе Иразиевич}

Кафедра управления бизнесом и сервисных технологий, старший преподаватель, аспирант Московский государственный университет пищевых производств, Россия, Москва

E-mail: gadzhimirzoevgi@mgupp.ru

Актуальность: Ковид-кризис разразившийся в 2020 году во всем мире в значительной степени изменил динамику и структуру продаж, в том числе повлиял на рынок легковых автомобилей. В результате на начало 2021 года в России образовался дефицит новых автомобилей и цены для потребителей выросли. Все это делает актуальным исследование сложившихся закономерностей на первичном рынке легковых автомобилей в России.

Цель: выявление и измерение тенденций на российском первичном рынке легковых автомобилей под влиянием ковид-кризиса.

Meтоды: для достижения поставленной цели были использованы такие статистические методы как табличный, графический, выборочный, коэффициентный, корреляционно-регрессионный.

Результаты: объем производства автомобилей в России в значительной мере подвержен влиянию локальных и мировых кризисов, в том числе ковид-кризиса 2020 года; несмотря на резкий рост внутристранового объема производства, уровень автомобилизации России в значительной мере отстает от мировых лидеров (разрыв в 2 раза), что объясняется низкой покупательной способностью населения и зависимостью автопрома от импорта комплектующих и запасных частей; динамика продаж в 2020-2021 году, в частности сезонность, в значительной степени отличается от предшествующей тенденции, что объясняется приостановкой производств, дефицитом комплектующих и снижающимися реальными доходами населения; дефицит новых легковых автомобилей в 2020 году привел к увеличению отпускных цен, что еще белее усугубило ситуацию и заложило тренд на снижение продаж авто.

Практическая значимость: основные положения и выводы статьи могут быть использованы в научной и практической деятельности при рассмотрении вопросов развития первичного рынка автомобилей в России под влиянием кризисных ситуаций внутристранового и мирового масштаба.

Ключевые слова: транспорт, первичный рынок автомобилей, стоимость, цена, статистика, факторы, качественные признаки, эконометрическая модель, взаимосвязь, предсказание.

\section{Введение}

Переход экономики России с плановой на рыночную модель в 1990-х годах привели к тотальному разрушению сформированных и нарождению новых институтов. Не исключением стала автомобильная промышленность, которая протерпела кардинальные изменения, так были закрыты заводы (к примеру, АМО Завод им. Лихачева), часть автопроизводителей была поглощена мировыми лидерами (к примеру, ПАО «АВТОВАЗ»), сформировано «отверточное» производство авто на территории РФ. Немаловажным фактом, оказывающим сдерживающее влияние на рынок автомобилей, является череда мировых и локальных кризисов, не исключением является ковид-кризис 2020 года, когда 
целые отрасли были приостановлены, что усугубило ситуацию, в частности, в 2021 году спрос в значительной степени превышает предложение, из-за этого дисбаланса цены на легковые автомобили резко пошли вверх, что на фоне низкой покупательной способности россиян делает недоступным покупку авто для большей части граждан России. В этой связи проводимое исследование является актуальным и своевременным и позволяет оценить недополучение прибыли производителей и дилеров, а также сформировать краткосрочные прогнозы развития рынка с учетом последствий ковид-кризиса.

Обращение к научным публикациям на тему развития отечественного рынка автомобилей обнаруживает несколько работ заслуживающих внимание, это: Багратуни С.А. [2], Бутов А.М. [3], Головастов Н.А. [4], Лейзин И.Б. [6], Магомедов Р. М. [7], Невежин В.П. [8], Сорокин В.В. [9] и др. В перечисленных исследованиях авторы рассматривают тенденции объемов продаж и цен на новые автомобили в России, но при этом в работах не указывается влияние ковид-кризиса на рассматриваемый рынок, что делает наше исследование актуальным и своевременным.

\section{Методы и модели}

Рассматривая совокупность статистических методов, использованных в исследовании, необходимо отметить следующие моменты: во-первых, разработка эконометрических моделей базируется на методике, изложенной в учебнике «Эконометрика» [16]; во-вторых, практические подходы к реализации статистических и эконометрических методов применительно к рынку автомобилей были взяты из работ Афанасьева В.Н. [1] и Цыпина А. П. [15].

В частности, для объема продаж трех нишевых брендов (Lada, Hyundai, Mercedes-Benz) была использована линейная модель с корректировкой уровней на сезонную волну:

$$
y_{t}^{\prime}=\left(a_{0}+a_{1} t_{t}\right) I_{i}
$$

где: $y$ - объем продаж автомобилей в России; $a_{0}, a_{1}$ - параметры модели;

$t$ - дискретная переменная характеризующая отношение уровней к конкретному периоду времени;

$I$ - индекс сезонности за 12 месяцев.

Получаемые в ходе исследования выводы и заключения, во многом зависят от наличия и полноты статистических данных, в своей работе мы использовали следующие источники информации.

Во-первых, это официальные данные о численности автомобилей в России, предоставляемые Федеральной службой государственной статистики РФ (Росстат), опубликованные в ежегодниках «Народное хозяйство РСФРС» (ретроспектива) и «Российский статистический ежегодник» (данные текущего периода).

Во-вторых, сведения World Bank характеризующие обеспеченность населения легковыми автомобилями (автомобилизация).

B-третьих, данные аналитического агентства Auto Vercity отражающие динамику продажи новых автомобилей в трех ценовых сегментах «премиум класс», «средний класс» и «дешевый сегмент».

Основываясь на приведенных источниках информации нами предлагается система показателей отражающая развитие автомобилизации в России и позиции страны относительно мировых лидеров, а также демонстрирующая подвижки в продажах под влиянием кавидкризиса: Производство легковых автомобилей в России, ед.; ВВП на душу населения, тыс. долл. США; Число автомобилей на 1000 населения, ед.; Динамика продаж новых автомобилей брендов Lada, Hyundai, Mercedes-Benz. Помимо динамической составляющей, в статье рассмотрена структура продажи новых автомобилей марок Lada, Hyundai, Mercedes-Benz, что позволяет выявить лидеров продаж и оценить структурные сдвиги.

\section{Результаты исследования}

Проводимое нами исследование будет разделено на две составляющих, это ретроспективная оценка ситуации в производстве легковых автомобилей и текущая ситуация с объемами продаж в условиях ковид-кризиса.

\section{1. Состояние и насыщенность рынка легковых автомобилей в России}

На рисунке 1 приведена динамика производства автомобилей в России, которая характеризуется поступательным наращиванием объемов. Так в 1960 г. в стране выпускалось всего 138,3 тыс. автомобилей, тогда как в 1970 г. выпуск превышал 250 тыс. авто, чему способствовало запуск Волжского автозавода. На момент распада СССР в стране выпускалось более 1 млн. автомобилей. Но с наступлением переходного периода, достигнутые результаты были утрачены. 


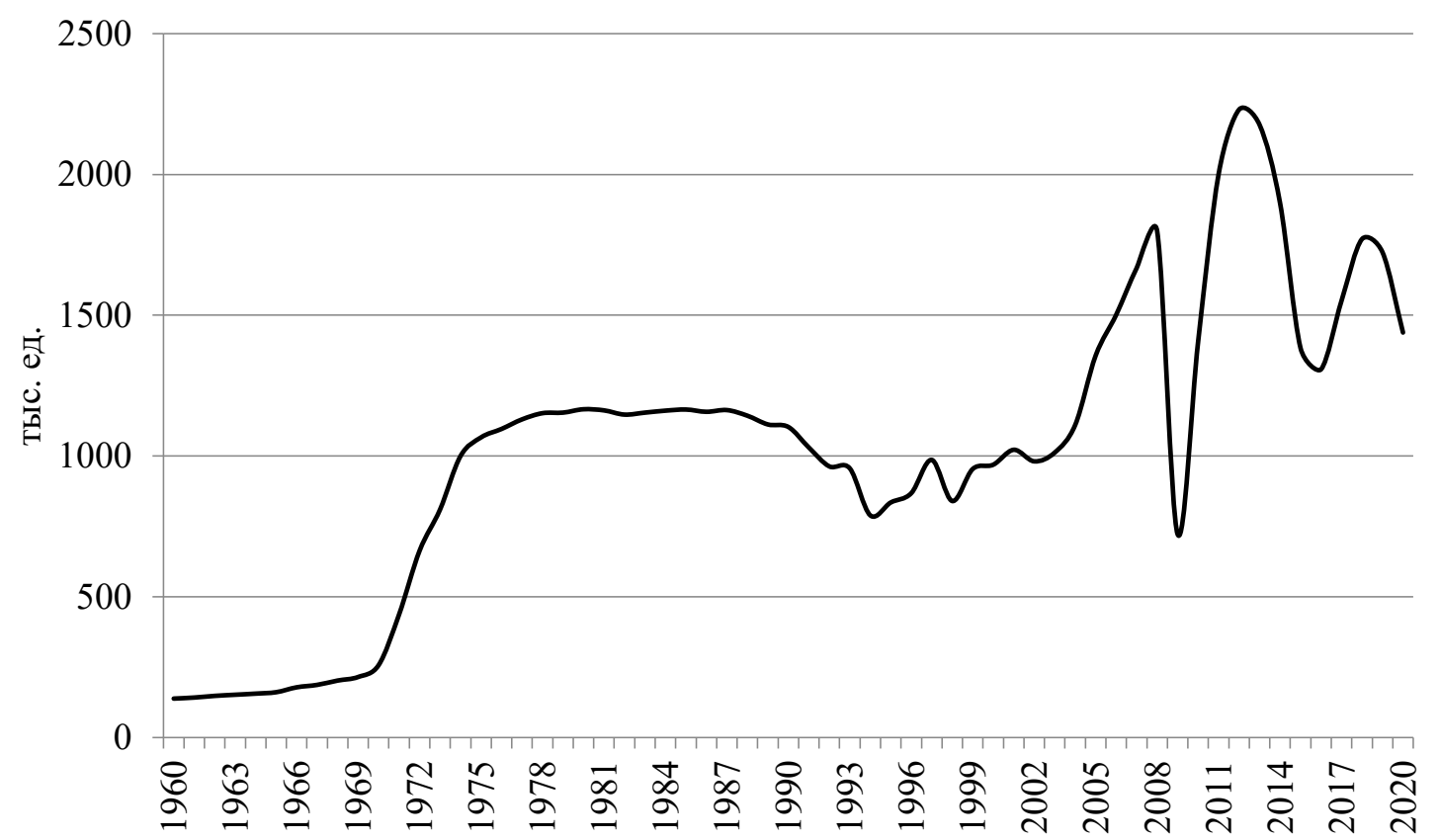

Pис. 1. Динамика производства легковых автомобилей в России: ретроспективная динамика, тыс. шт. Источники: составлено на основе данных «Народное хозяйство РСФРС» (до 1990 г.), «Российский статистический ежегодник» (1991-2003 гг.), Auto Vercity (2004-2020 гг.)

Приведенные на рисунке 1 данные наглядно показывают рост выпуска автомобилей в советский период до 1990 года. Далее наблюдается «проседание» глобального тренда в связи с мировыми и локальными кризисами. Так первый провал наблюдается в 1990-х годах, что связано с переходными процессами и формированием новых институтов. Мировой кризис 2008 года негативным образом отразился на производите, оно откатилось до уровня 1970-х годов. Валютный кризис 2014 года стал не столь разрушительным для отрасли, значения откатились до уровня начала 2000-х годов. Текущий ковидкризис также повлиял на выпуск автомобилей, но уровень падения не столь значителен, что указывает на формирование устойчивости системы к шоковым ситуациям.

Резкое увеличение объемов производства связано не с достижениями российского автопрома, а с заградительными барьерами на импорт готовых автомобилей. В результате большинство мировых производителей построили сборочные линии на территории РФ, на которые завозят элементы конструкций и собирают готовые автомобили. При этом наблюдается низкая локализация конечного изделия, этим и объясняются «провалы» в производстве (перебои с поставками частей в кризисные периоды), так как любой кризис в России неминуемо ведет к повышению курса доллара (евро) относительно рубля и как результат элементы конструкции автомобиля дорожают.

Рост внутреннего производства ведет к увеличению показателя автомобилизации в России, для оценки этого явления обратимся к данным представленным на рисунке 2 .

Согласно информации World Bank, приведенной на рисунке 2, положение России в области автомобилизации сопоставимо с развивающимися странами и странами с переходной экономикой. Так в 2019 году на 1000 жителей страны приходилось 388 автомобилей, примерно такие же показатели в таких странах как Сербия, Латвия, Бразилия и Оман. Тогда как в развитых странах величина показателя достигает 700 и более автомобилей на 1000 населения: Новая Зеландия - 837 авто на 1000 населения; США 816; Мальта - 766; Финляндия - 752; Италия 655 ; Япония -649 .

Таким образом можно сделать вывод что в России существует резерв увеличения автомобилизации, который сдерживается объективными факторами: низкой покупательной способностью населения, низкой инфраструктурой автомобильных дорог, высокой зависимостью от импорта комплектующих, отсутствием российского производства, не зависящего от мирового рынка. 


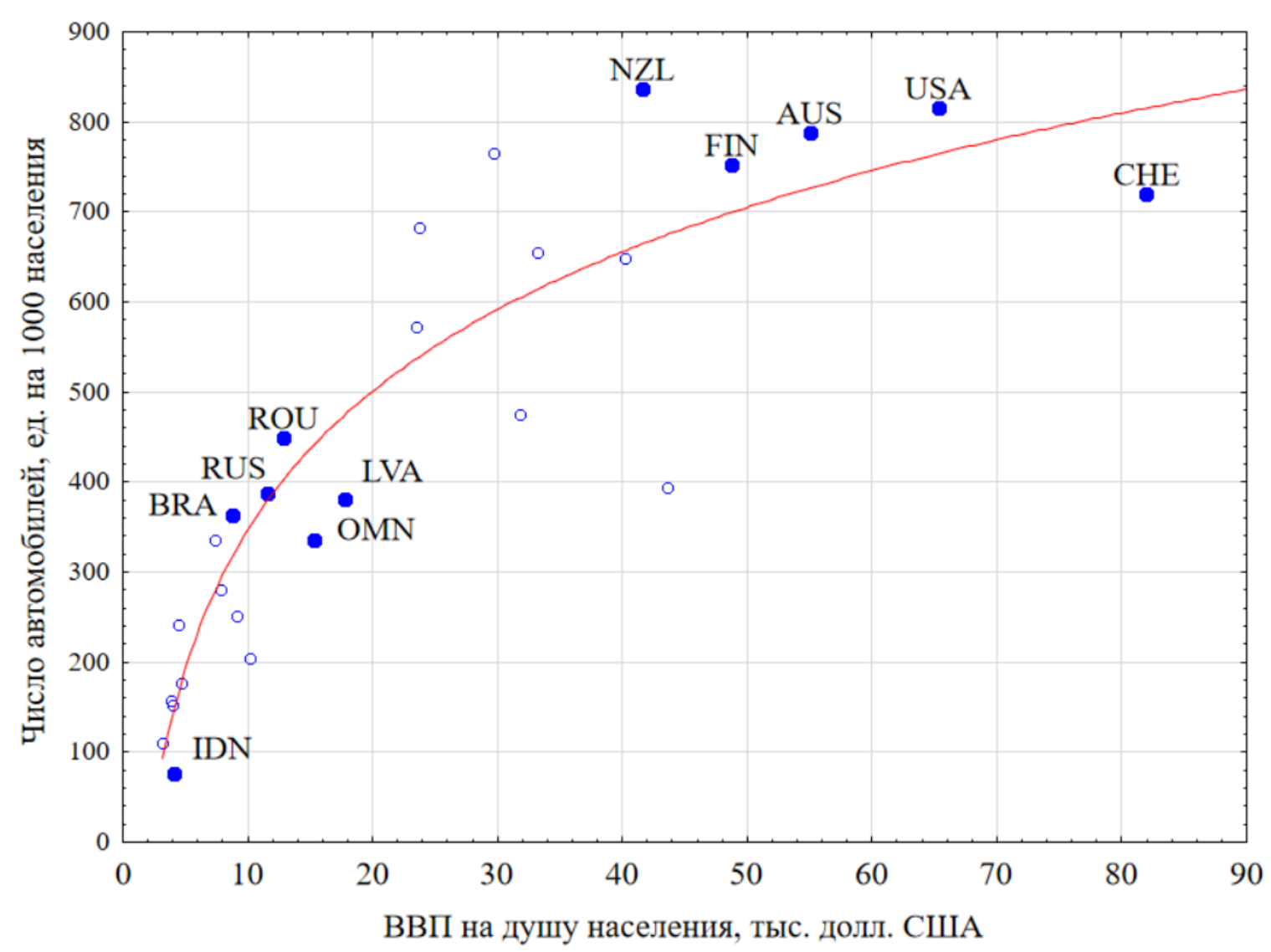

Puc. 2. Кривая насыщенность рынка автомобилей в 2019 году

Источник: составлено авторами по материалам публикации «List of countries by vehicles per capita» [19] и данным World Bank [18]

Анализируя зависимость, представленную на рисунке 2, стоит отметить, что соотношение показателей автомобилизации и уровня жизни развивается по экспоненте, т.е. с увеличением состоятельности граждан наблюдается взрывной рост, который имеет точку насыщения, таким образом можно заключить, что вне зависимости от благосостояния нации, довести показатель обеспеченности автомобилями до 100\% уровня не представляется возможным.

2. Состояние российского рынка автомобилей в условиях ковид-кризиса

События 2020 года, связанные с борьбой против пандемии нового вируса Covid-19, отразились на многих отраслях экономики России, в первую очередь пострадала сфера услуг, строительная отрасль и промышленное производство. Не исключением является услуги по продажи автомобилей и деятельность по производству (сборке) новых автомобилей. Поэтому обратимся к данным приведенным на рисунке 3 и проанализируем динамику продаж автомобилей трех марок Lada, Hyundai, Mercedes-Benz за период 2017-2020 гг., наш выбор объясняется желанием сопоставить уровень изменений под влиянием ковид-кризиса в трех классах: премиум, средний класс и дешевый сегмент.

Как показано на рисунке 3, сложившаяся в 2018-2019 гг. сезонная волна объемов продаж автомобилей трех рассматриваемых брендов, претерпела значительные изменения в 2020 году. В частности ежегодный рост продаж в марте месяце был прерван ковид-кризисом, далее в сентябре отчетного года наблюдаем компенсационный рост.

Изменения привычного ритма функционирования первичного рынка легковых автомобилей во многом обусловлено влиянием ковидкризиса.

Во-первых, была приостановлена работа ряда производителей (готовых автомобилей и комплектующих к ним). Количество смен на сборочных заводах была снижена, так в период локдауна (lockdown) 2020 года, заводы работали в 1-2 смены, тогда как в обычном ритме производство осуществляется в 4 смены. 


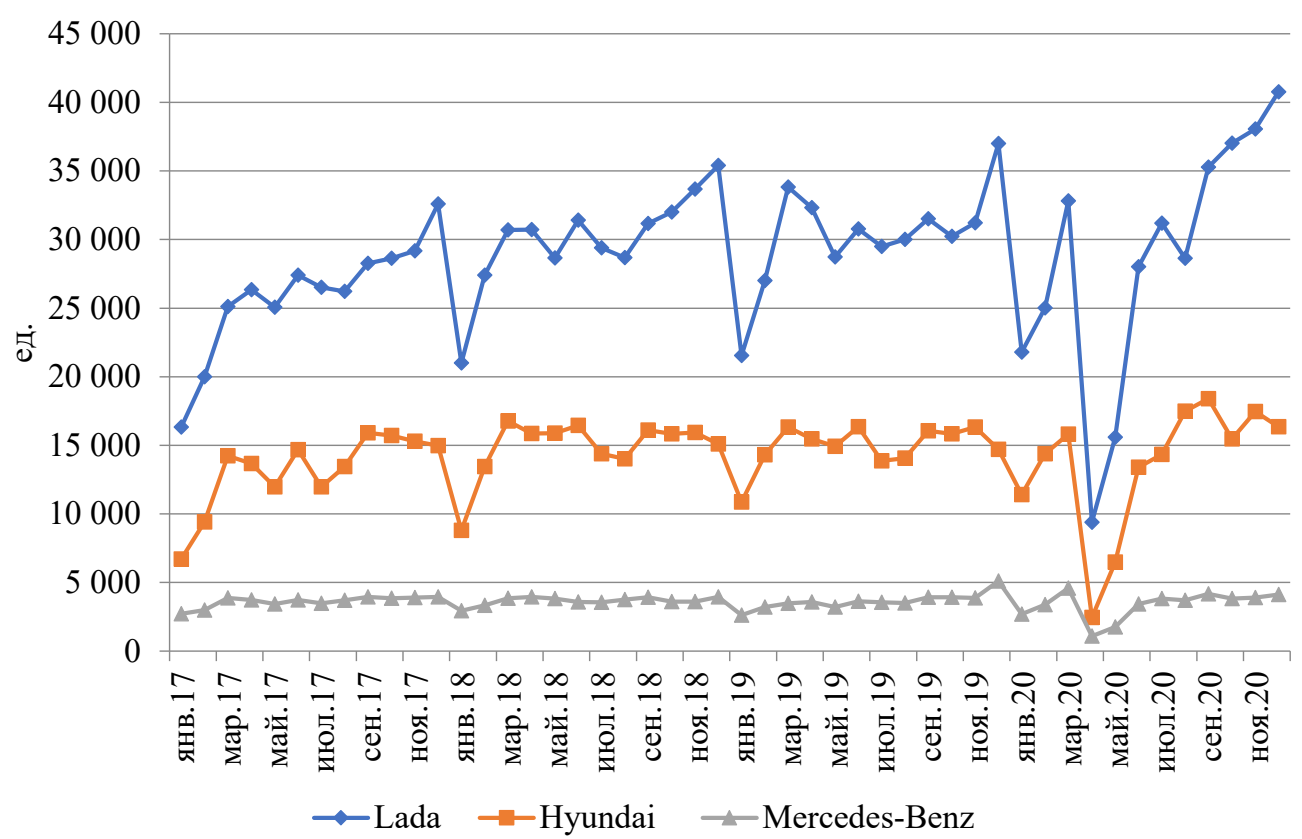

Puc. 3. Динамика продаж новых автомобилей брендов Lada, Hyundai, Mercedes-Benz в 2017-2020 гг. Источник: выполнено автором на основе данных Auto Vercity [10]

Во-вторых, приостановка заводов в Китае сформировала дефицит на чипы на автомобили, в результате возникли перебои в последующих технологических цепочках.

В-третьих, покупатель не имел возможности приобретать новые автомобили по причине остановки работы автосалонов и дилерских центров в России.

Для оценки асинхронности продаж в 2020 году от возможных (вероятных), при сохранении тенденций 2017-2019 гг., оценим линейный тренд на периоде 2018-2019 гг., и построим прогноз на 2020 год с учетом сезонной волны (согласно методологии Афанасьева В.Н. [1]) (табл. 1).

Результаты построения эконометрической модели и прогноз на один шаг, наглядно показывают, что предсказанные значения отличаются от фактических уровней объема продаж автомобилей, сформировавшихся под влиянием ковид-кризиса. Как видим, по всем трем брендам наблюдается недополучение (отрицательное значение) прибыли в результате отклонения от сложившейся в 2017-2019 гг. траектории.

Обратимся к структуре продаж (табл. 2) и выявим лидеров продаж по трем выделенным брендам и проанализируем изменения в структуре продаж [11, 17].

Согласно приведенным в таблице 2 данным, продажи Granta занимают более 30\% всех проданных автомобилей марки Lada, что объясня- ется демократичной ценой, которая в 2021 году стартует с отметки 531900 руб. [12] в результате в 2019 году было продано 75,1 тыс. автомобилей, тем не менее это на 20,9\% меньше чем в 2019 году. В модельном ряду марки Hyundai лидерами являются Creta и Solaris, что обеспечивается комфортом и ценами - от 509 тыс. руб. и 378 тыс. руб. соответственно [14].

Линейка бренда Mercedes-Benz шире остальных двух рассматриваемых брендов и насчитывает порядка 20 различных моделей, потребитель может выбрать автомобиль на свой вкус, соответственно удельные веса продаж распределяются более равномерно. Лидерами продаж являются GLC-Class и E-Class, цены по которым в текущем году стартуют от 5,144 и 4,920 млн. руб. соответственно [13].

Сопоставляя цены представленных моделей трех брендов, можно констатировать незначительный разрыв между отечественными автомобилями и автомобилями Hyundai, но при этом наблюдается колоссальный отрыв премиум-авто. Тем не менее объемы продаж указывает, что все марки и бренды востребованы в России.

Обращаясь к ценам и ценовой политики, необходимо указать на тот факт, что диспропорции между спросом и предложением привели к росту цен на имеющиеся автомобили. Так по данным портала Matador Tech [5] в 2021 году по сравнению с 2020 г. цены на автомобиле преми- 
Таблица 1. Фактическая динамика и прогноз продаж новых легковых автомобилей брендов Lada, Hyundai, Mercedes-Benz в(на) 2020 г.

\begin{tabular}{|c|c|c|c|c|c|c|c|c|c|}
\hline \multirow{2}{*}{ Период } & \multicolumn{3}{|c|}{ Lada } & \multicolumn{3}{c|}{ Hyundai } & \multicolumn{3}{c|}{ Mercedes-Benz } \\
\cline { 2 - 11 } & факт & прогноз & $\begin{array}{c}\text { откло- } \\
\text { нения }\end{array}$ & факт & прогноз & $\begin{array}{c}\text { откло- } \\
\text { нения }\end{array}$ & факт & прогноз & $\begin{array}{c}\text { откло- } \\
\text { нения }\end{array}$ \\
\hline янв.20 & 21790 & 27930 & -6140 & 11397 & 11866 & -469 & 2704 & 3530 & -826 \\
\hline фев.20 & 25002 & 30269 & -5267 & 14385 & 13696 & 689 & 3377 & 3827 & -450 \\
\hline мар.20 & 32808 & 33547 & -739 & 15819 & 16027 & -208 & 4581 & 4196 & 385 \\
\hline апр.20 & 9396 & 33341 & -23945 & 2443 & 15584 & -13141 & 1089 & 4180 & -3091 \\
\hline май.20 & 15580 & 32642 & -17062 & 6493 & 14967 & -8474 & 1760 & 4050 & -2290 \\
\hline июн.20 & 28020 & 35205 & -7185 & 13406 & 15356 & -1950 & 3428 & 4238 & -810 \\
\hline июл.20 & 31180 & 28743 & 2437 & 14342 & 11731 & 2611 & 3830 & 3712 & 118 \\
\hline авг.20 & 28621 & 31081 & -2460 & 17478 & 13561 & 3917 & 3711 & 4010 & -299 \\
\hline сен.20 & 35264 & 34360 & 904 & 18397 & 15892 & 2505 & 4171 & 4379 & -208 \\
\hline окт.20 & 37019 & 34153 & 2866 & 15458 & 15449 & 9 & 3816 & 4363 & -547 \\
\hline ноя.20 & 38064 & 33454 & 4610 & 17469 & 14832 & 2637 & 3899 & 4233 & -334 \\
\hline дек.20 & 40768 & 36017 & 4751 & 16354 & 15221 & 1133 & 4125 & 4421 & -296 \\
\hline Сумма & 343512 & 390742 & -47230 & 163441 & 174184 & -10743 & 40491 & 49138 & -8647 \\
\hline
\end{tabular}

Источник: выполнено автором на основе данных Auto Vercity [10]

Таблица 2. ТОП3 продаваемых марок трех брендов в 2019 г.: Lada, Hyundai, Mercedes-Benz, \% от общего объема продаж

\begin{tabular}{|c|c|c|c|c|c|}
\hline \multicolumn{2}{|c|}{ Lada } & \multicolumn{2}{c|}{ Hyundai } & \multicolumn{2}{c|}{ Mercedes-Benz } \\
\hline Granta & 32,9 & Creta & 37,7 & GLC-Class & 17,6 \\
\hline Vesta & 28,7 & Solaris & 37,4 & E-Class & 16,5 \\
\hline Largus & 14,3 & Tucson & 11,2 & GLE & 12,9 \\
\hline
\end{tabular}

Источник: выполнено автором на основе данных Auto Vercity [10]

альных марок увеличились в значительной степени, к примеру, автомобили Mercedes-Benz в среднем подорожали на 25,2\%, BMW - на 16,7\%; Cadillac - на 12,7\%.

Что касается премиям сегмента, то уже в середине 2020 года аналитики прогнозировали существенный рост цен, так как именно этого класса чаще всего импортируются в Россию, а значит на их стоимость влияют курсовые разницы.

Средний сегмент подорожал в меньшей степени, к примеру, цена Renault Arkana прибавила 10\%, Renault Duster - 11,6\%, Kia Ceed - 13\%, Skoda Rapid - 10,6\%, Volkswagen Polo - 9\%, Hyundai Creta - 5,4\%, Renault Logan - 6,7\%, Hyundai Solaris и Kia Rio - 6,5\%

Более «дешевый» сегмент, представленный отечественными марками, следуя за общерыночными трендами, также подорожал, к примеpy, Lada Vesta прибавила 7,4-9,9\%, Lada Granta 5,6-6,3\%, Lada Niva Legend - 5,4\%.

Таким образом, изменения в сезонности про- даж новых автомобилей в России, а также повышенный спрос в конце 2020 г. начале 2021 г. обусловлен комплексом факторов, которые трудно поддаются прогнозированию и управлению.

\section{Заключение}

Подводя итог проведенного исследования влияния ковид-кризиса на объем продаж новых автомобилей в России в 2020 году, можно сформулировать ряд выводов.

1. Динамика производства новых легковых автомобилей после 1990 года подвержена влиянию локальных и международных кризисов, самым «разрушительным» из которых был кризис 2008 года, в результате которого производство откатилось до уровня 1970-х годов. Установленная закономерность обусловлена наличием ряда объективных факторов, и прежде всего это сильная зависимость внутреннего производства от импорта комплектующих и запасных частей.

2. Несмотря на значительные успехи в производстве автомобилей на территории России, уровень автомобилизации еще далек от разви- 
тых стран, в которых на 1000 населения приходится более 700 автомобилей против 388 автомобилей в РФ. Но достижение такого результата сдерживается низкой покупательной способностью населения при высокой цене автомобиля, а также фактическим отсутствием российского автопрома.

3. В 2020 году наблюдается серьезные изменения в сезонности продаж новых автомобилей в России, что обусловлено комплексом факторов, которые трудно поддаются прогнозированию и управления, а именно: дефицит автомобилей; снижение объемов выпуска продукции автозаводами; закрытие дилерских центров.

4. Результатом сложившейся ситуации на российском рынке новых автомобилей, а именно диспропорции спроса и предложения, в конце 2020 г. начале 2021 года наблюдалось увеличение отпускных цен, что на фоне падающих реальных доходов населения приведет в среднесрочной перспективе к снижению объемов проданных легковых автомобилей.

\section{Библиографический список}

1. Афанасьев, B. Н. Эконометрика в пакете STATISTICA: учебное пособие по выполнению лабораторных работ / В.Н.Афанасьев, А.П.Цыпин.- Оренбург: ИП Кострицын, 2010.- 196 с.

2. Багратуни С. А. Динамика рынка новых легковых автомобилей в России за 2013-2017 гг / С. А. Багратуни // Журнал правовых и экономических исследований. - 2019. - № 1.- С. 96-102.

3. Бутов А. М. Рынок новых легковых автомобилей [Электронный ресурс] / Центр развития ВШЭ.- Режим доступа: https://www.hse.ru/data/2020/12/27/1342499626/Рынок\%20новых\%20легковых\%20автомобилей-2020. pdf

4. Головастов Н.А. Проблемы развития российского рынка легковых автомобилей / Н.А. Головастов // Менеджмент: теория и практика. - 2019.- № 1-3.-С. 61-63.

5. Какие автомобили подорожали в 2021 году и почему [Электронный ресурс] / Matador Tech. - Режим доступа: https://matador.tech/articles/kakie-avtomobili-podorozali-v-2021-godu-i-pocemu

6. Лейзин И.Б. Анализ автомобильного рынка России / И.Б.Лейзин, А.С.Неуструева // Инновационная экономика: перспективы развития и совершенствования.- 2020.- № 7(49).- С. 118-124.- DOI 10.47581/2020/10.23.PS85/IE/7/49.018.

7. Магомедов Р. М. Перспективы развития отечественной автомобильной промышленности / Р. М. Магомедов // Самоуправление.-2021.- № 2(124). - С. 386-390.

8. Невежин В.П. Прогнозирование стоимости легковых автомобилей среднего класса / В.П.Невежин // Автомобильная промышленность. - 2020.-№ 6.- С. 1-5.

9. Сорокин В.В. Состояние рынка легковых автомобилей как индикатор развития экономики России / В. В. Сорокин // Modern Economy Success. - 2021.- № 2.- С. 186-190.

10. Статистика и спрос на новые автомобили в России [Электронный ресурс] / Auto Vercity.- Режим доступа: https://auto.vercity.ru/statistics/sales/europe/russia/

11. Улитина Е.В. Статистика: учебное пособие / Е. В.Улитина, О.В.Леднева, О. Л. Жирнова.- Москва: Московский финансово-промышленный университет «Синергия», 2013. - 320 с.

12. Цена на модели Lada [Электронный ресурс] / LADA. - Режим доступа: https://www.lada.ru/cars

13. Цена на модели Mercedes Benz [Электронный ресурс] / Официальный дилер cedes Benz Авилон Москва.Режим доступа: https://sales.mercedes-avilon.ru/cars/glc_class/

14. Цены на модели Hyundai [Электронный ресурс] / СТС-Моторс.- Режим доступа: https://ctcmotors.ru/auto/ hyundai/

15. Цыпин А.П. Эконометрическое моделирование влияния факторов на цены вторичного рынка легковых автомобилей Г. Оренбурга / А. П.Цыпин, Л. Р. Фаизова // Азимут научных исследований: экономика и управление.-2018.- Т. 7.- № 3(24).- С. 308-311.

16. Эконометрика: учебник / В.Н.Афанасьев, Т.В.Лебедева, Т.В.Леушина, А.П.Цыпин; Под редакцией В. Н. Афанасьева. - Оренбург: ООО ИПК «Университет», 2012. - 402 с.

17. Яковенко Л. И. Статистика: учебное пособие / Л. И. Яковенко, А. В. Лосева.- Новосибирск: Новосибирский государственный технический университет, 2016. - 276 с.

18. GDP per capita (current US\$) [Электронный ресурс] / World Bank. - Режим доступа: https://data.worldbank.org/ indicator/NY.GDP.PCAP.CD

19. List of countries by vehicles per capita [Электронный ресурс] / Википедия.- Режим доступа: https://wikizero. com/en/List_of_countries_by_vehicles_per_capita 